\title{
REDUCCIÓN DE INDIOS INFIELES EN LA MONTAÑA DEL CHOL: LA EXPEDICIÓN DEL SARGENTO MAYOR MIGUEL RODRÍGUEZ CAMILO EN 1699
}

\author{
Francisco LuIS JimÉnEZ ABollado \\ Universidad Autónoma del Estado de Hidalgo
}

\begin{abstract}
REsumen: En 1699, entre febrero y marzo, se produjo una entrada a la Montaña del Chol, comandada por el Sargento Mayor don Miguel Rodríguez Camilo. Éste era castellano del Castillo de San Felipe del Golfo Dulce y Alcalde Mayor del Puerto de Santo Tomás de Castilla y del pueblo de San Pedro Amatique. La entrada fue una incursión más de las habidas en estos territorios del sureste maya para reducir a los denominados "indios infieles" y huidos diseminados por el área y enviada desde la Audiencia de Guatemala. La pricipal diferencia de esta entrada con las anteriores estribaba en que en esta ocasión no había presencia de religiosos en la misma. Sin embargo, el objetivo era la reducción de dichos indios, y la citada penetración se produjo en plena acometividad por incorporar el área inmediata a las Montañas del Chol, El Petén, al dominio colonial.
\end{abstract}

Palabras clave: Chol Manché, Expedición, Reducción, Mopanes, Montaña, Petén.

Aastract: In 1699, between February and March, the Sergeant Major don Miguel Rodríguez Camilo carried out an entrada to the Mountain of the Chol. He was the Castellano of the Castillo de San Felipe del Golfo Dulce and Major Mayor of the Puerto de Santo Tomás de Castilla and of the village of San Pedro Amatique. The entrada was another incursion in these territories of the Mayan south-east to reduce the so called "unfaithful Indians" and escaped spread by the area and envoy from the Audiencia of Guatemala. The difference between this entrada with the previous ones was the fact that on that in this occasion there was no presence of religious in the same one. Nevertheless, the purpose was the reduction of the above mentioned Indians, and the penetration took place with full aggressiveness for incorporating the immediate area into the Mountains of the Chol, The Peten, into the colonial control.

Krrwords: Chol Manché, Expedition, Reduction, Mopanes, Mountain, Peten.

RECEPCION: 26 de octubre de 2007.

ACEPTACIÓN: 14 de octubre de 2008. 



\title{
REDUCCIÓN DE INDIOS INFIELES EN LA MONTAÑA DEL CHOL: LA EXPEDICIÓN DEL SARGENTO MAYOR MIGUEL RODRÍGUEZ CAMILO EN 1699
}

\author{
Francisco Luis JimÉnez Abollado \\ Universidad Autónoma del Estado de Hidalgo
}

Cuando a partir del primer cuarto del siglo xvl los españoles iniciaron sus entradas en la región central del área maya —-donde se extienden los actuales estados de Tabasco, Chiapas, Campeche, Quintana Roo en México, y los departamentos de Verapaz, Petén, Quiché y Huehuetenango en Guatemala_, encontraron un variado mapa étnico pero originario de un tronco común, el maya. Chontales, acalanes, itzáes, cehaches, mopanes y choles, divididos éstos en diferentes grupos como manchés, loquenes, xocmoes y axoyes, vivieron en carne propia la presión provocada por la llegada de los conquistadores y primeros pobladores hispanos, así como los posteriores intentos de colonización y evangelización. Las fugas, huidas, migraciones y traslados fueron una constante para estos pueblos mayas a partir de entonces.

La movilidad durante el periodo colonial, en todas sus acepciones, tenía la intención de evadir el control hispano (económico, político y religioso). Numerosos estudios han aclarado las relaciones entre los pueblos que se encomendaron a conquistadores y sus descendientes, los huidos o fugitivos y algunas regiones bien pobladas y organizadas, fuera del alcance del poder colonial. ${ }^{1}$ Estas últimas se convirtieron en interesantes atrayentes de los muchos pueblos no organizados y diseminados por el interior de la región central maya. Fue el caso de los itzáes. Señala Laura Caso Barrera que la presencia del señorío itzá fue fundamental para explicar estos movimientos de población y resistencia al régimen colonial en este extenso territorio del espacio cultural maya que arriba se menciona. Los itzáes integraron en su círculo de relaciones a los pueblos de huidos, organizándolos política y económicamente, pero jugando un papel primordial las relaciones de intercambio con ellos. Los pueblos choles de la región, lacandones e indios huidos de zonas controladas por los españoles, usaron el intercambio con los itzáes para aprovisionarlos de herramientas, sal, cacao, vainilla y achiote. ${ }^{2}$

\footnotetext{
${ }^{1}$ Al respecto, para el área maya, véanse: Jones (1990 y 1998), Stone (1932) Caso (2002); Chávez (2001), De Vos (1988) y Bracamonte (2001).

${ }^{2}$ Caso (2002: 378-381).
} 
Una de las zonas no organizadas y escasamente pobladas de esta área en torno al territorio itzá era la que ocupaban diversos grupos de filiación maya. Choles manchés y mopanes al sur y sureste del Itzá, choles al suroeste y chontales acalanes al noroeste. ${ }^{3}$ En este trabajo vamos a centrarnos especialmente en los mopanes y choles manchés, pues parte de sus áreas de asiento fueron recorridas por la expedición del Sargento Mayor Miguel Rodríguez Camilo en 1699, en el ángulo sureste del Petén, el sur de Belice y la región del Golfo Dulce, dentro del espacio cultural y territorial conocido como el sureste de las Tierras Bajas Mayas. Se trataba ésta de una zona fronteriza entre el Reino, Audiencia y Capitanía General de Guatemala y la Gobernación de Yucatán. La región que habitaban estos grupos a fines del siglo xvı es selvática tropical, con abundante flora y fauna; un clima propio de grandes lluvias y húmedo, así como atravesada por ríos caudalosos y la presencia de lagunas y aguadas. Thompson describe este territorio como una región baja de caliza que no se alza más de $215 \mathrm{~m}$ sobre el nivel del mar, con una fuerte precipitación pluvial de hasta $3 \mathrm{~m}$ al año en el sur, y cubierta por una red de ríos y muchos extensos pantanos, donde por "doquier se halla una espesa selva pluviosa. Tiene montañas, que se extienden desde el sur de Belice hasta la República de Honduras, y sabanas no muy extensas". ${ }^{4}$ Condiciones geográficas éstas, que unidas a otras razones como faltas de riquezas, ausencia de grandes poblaciones, escasez de misioneros y, especialmente, nulo interés de los españoles, llevaron a esta región a caer en un completo olvido durante cerca de dos siglos.

Choles manchés, loqueguas o loquenes, xocmoes, axoyes y mopanes habitaban el citado territorio, haciendo la salvedad que de estos grupos mayas únicamente los mopanes eran un subgrupo de la familia linguística maya peninsular, mientras que los demás grupos citados pertenecían al subgrupo cholano. ${ }^{5} \mathrm{El}$ trato de estos pueblos con sus vecinos era muy frecuente. El área, al ser cruzada por bastantes ríos caudalosos, afluentes y arroyos, permitía estos contactos, que no se limitaban a los meramente humanos, sino que se extendían a los comerciales y culturales. Existían grupos cholanos en el área del Golfo Dulce, en torno al lago Izabal, que según Stone hablaban mopán y sirvieron de intérprete para las entradas y expediciones que se hicieron desde Guatemala. ${ }^{6}$

\section{Entradas y expediciones}

La presencia española en las Tierras Bajas Mayas arrancó en 1525 con la travesía de Hernán Cortés camino de Honduras-Hibueras para poner fin a la insubordina-

\footnotetext{
3 Jones (1998: 5-7).

${ }^{4}$ Thompson (1975: 74).

5 Véase al respecto Schumann $(1997,2000)$. Thompson $(1975: 89)$ señala que el mopán difería poco del yucateco. Igualmente el cronista dominico fray Francisco Ximénez manifiesta que los mopanes hablaban yucateco o una lengua parecida a la que hablaban los del itzá, distinta del chol, apud Von Houwald (1979: 69).

6 Jones (1998: 5).
} 
ción de Cristóbal de Olid. Desde esta fecha hasta principios del siglo xvı, debido a la inconstancia de las entradas y expediciones, el área permanecía casi invariable. Era muy complicado someter la resistencia de los indígenas de estas áreas, que se ponía de manifiesto al retirarse a zonas de difícil acceso o mediante las armas, ya sea contra religiosos, soldados o incluso indios cristianizados. ${ }^{7}$

Es a partir de la segunda mitad del siglo xvı cuando empiezan a desarrollarse en esta área las denominadas "entradas" y "expediciones". En palabras de García Añoveros las "entradas" y "expediciones" intentaron "soslayar los problemas jurídicos y morales que el término conquista implica". ${ }^{8}$ En la Instrucción de 1556 y en la Ordenanza de 1573 ya se hicieron diferencias entre ambos conceptos. La "entrada" era una partida encabezada por religiosos acompañados de indios y soldados de escolta, cuya misión era convertir y reducir indígenas con un carácter pacífico, mientras que la "expedición" era un grupo armado acompañado de religiosos, que se emplea como último recurso para someter a los indígenas. ${ }^{9}$

A partir de 1603, cuando los dominicos de la Verapaz iniciaron de una manera esporádica y poco sistemática su penetración en territorio chol, se empezó a tener noticia de estos pueblos mayas. El desconocimiento por parte de los españoles de los grupos indígenas que habitaban la zona obligó a autoridades civiles y religiosas a elaborar numerosas Descripciones y Relaciones, que junto a la información procedente de las Crónicas que igualmente se elaboraron, nos han proporcionado un importante caudal de información etnográfica. Como fuentes documentales primarias debemos destacar la "Relación del Padre Fray Juan Ezquerra O.P. sobre la Provincia del Manché, $1605 ",{ }^{10}$ así como los "Autos hechos sobre la reducción del Chol y Lacandón y Mopán, 1695". ${ }^{11}$ Pese a este empeño, hasta fines del siglo xvII mucho de los esfuerzos por someter y posteriormente convertir a estos pueblos fracasaron. La geografia del terreno, el poblamiento disperso y la facilidad de los indígenas para huir de las reducciones que se hicieron, unidos a que las entradas y expediciones no fueron constantes ni firmes, fueron factores que explican el fracaso de estos intentos.

A fines del siglo xvil el panorama tornó a cambiar en esta región cuando la Corona española inició una nueva política en relación con la pacificación de ciertas áreas no dominadas y controladas por indígenas proclives a huir de las reducciones y pretender realizar alzamientos y provocar rebeliones. ${ }^{12}$ García Añoveros

\footnotetext{
7 Suñe (1994: 161).

${ }^{8}$ García (1985: 23).

${ }^{9}$ Suñe (1994: 161), Suñe presenta en su trabajo una completa relación de expediciones, entradas y exploraciones realizadas en esta zona y alrededores entre 1506 y 1697, Suñe (1994: 179-180).

${ }^{10}$ Archivo General de Indias (AGI), Guatemala, 181.

${ }^{11}$ AGI, Guatemala, 152-153. Las crónicas que pueden completar la información primaria son las que escribieron Tovilla (1985), Ximénez (1975) y León Pinelo (1960).

${ }^{12}$ Caso (2002: 249) y Von Houwald (1979: 93) senalan que el antecedente de esta nueva política fue una real cédula del 14 de mayo de 1686, cuyo contenido muestra las intenciones políticas, económicas y religiosas de la Corona a fines del siglo xvu en relación con sus territorios no dominados en América.
} 
sostiene que éstas son en realidad expediciones de conquista, aunque los documentos oficiales eviten enunciar la palabra conquistar. ${ }^{13}$ La región central del área maya, desde el sur de la Gobernación de Yucatán hasta Guatemala estaba incluida en este proyecto. Además de la necesidad de reducir a los indios de esta abandonada región, estaba la perentoria obligación de abrir una vía de comunicación entre Mérida y Campeche con Guatemala. Tanto las autoridades metropolitanas como las de la Gobernación de Yucatán y las de la Capitanía General de Guatemala metropolitanas vieron la necesidad de comunicar el Golfo de México con el Pacífico; una nueva ruta terrestre entre dos océanos fuera del alcance de corsarios y piratas, que tenía asimismo el escollo de topar con indígenas rebeldes en su curso; indígenas que desde la llegada de los españoles encontraron en ese territorio un espacio para no caer ni sucumbir en las garras del sistema colonial. Así, junto a la idea de abrir el camino estaba el objetivo de acabar con la situación que causaba gran cantidad de indígenas pacíficos que procedentes de sus pueblos y comunidades llegaban a estos parajes en busca de refugio. Pero también someter, convertir y reducir a los indómitos itzáes y comunidades aliadas, asentados en sus entrañas. No sólo el comercio se podría beneficiar con la apertura de esta nueva ruta, sino que la Corona encontraba un filón importante de entradas procedentes del tributo y las obvenciones.

En 1695 las autoridades de la Audiencia de Guatemala, con su presidente Jacinto de Barrios Leal, y de la Gobernación de Yucatán, a través de su gobernador interino Martín de Ursúa y Arizmendi, acordaron unir sus fuerzas para reducir a los itzáes y a las demás comunidades mayas que en las tierras bajas estaban sujetas a éstos o estaban apartadas, huidas y sin someter a las autoridades virreinales. La expedición que partió de Guatemala, al mando del oidor de su Audiencia, Bartolomé de Amezquita, tenía como misión "subyugar militarmente la región y anticiparse a Ursúa", intentando atraer hacia Guatemala los beneficios que esperaban de esta conquista y que temían que se apoderasen de ellos la expedición yucateca. Amezquita tuvo muchos problemas para llegar a su objetivo final, destacando la falta de medios, el temor a las deserciones de los indígenas que le acompañaban y, fundamental, sus faltas de experiencia y conocimiento del terreno. Ello significó ralentizar su expedición hasta que el nuevo presidente de su Audiencia, Gabriel Sánchez de Berrospe, avanzado 1696, ordenara suspenderla y regresar a Guatemala ${ }^{14}$ En marzo de 1697 , la expedición yucateca al mando de don Martín de Ursúa logró tomar la laguna y la isla de los itzáes no sin dificultades y problemas con las nuevas autoridades yucatecas que desconocieron la labor de Ursúa. A pesar de estas expediciones, la toma de la laguna y de su isla, así como la constitución en estos lugares de un presidio, buena parte de El Petén y sus áreas vecinas seguían bajo control de itzáes huidos, sus aliados y otras comunidades diseminadas.

\footnotetext{
${ }^{13}$ García (1985: 24).

${ }^{14}$ Ruz (1992: 341, 346-347).
} 
Para las autoridades españolas era necesario afianzar y asegurar lo logrado. $\mathrm{Si}$ el camino yucateco al corazón de la región central del área maya estaba perfilado, no estaba así el que debía llegar desde Guatemala. Nuevas cédulas reales, a fines de 1698 , ordenaban a autoridades yucatecas y guatemaltecas juntar sus caminos. El gobernador de Yucatán, Roque de Soberanis, adversario y rival de Ursúa, prestó a éste, más por obediencia debida que por convicción personal, la ayuda que necesitaba. Por su parte, Sánchez de Berrospe, desde Guatemala, financió dos compañías para abrir el camino al corazón de los itzáes. La idea era ir reduciendo y atrayendo paulatinamente a los indígenas, tener abierto e ir habilitando los caminos y que existiera un tráfico fluido. Sin embargo, el clima, las enfermedades, el hambre y por supuesto las dificultades para someter a los indígenas hicieron fracasar esta campaña, y en mayo de 1699 retornaron las diferentes compañías a sus puntos de orígenes. En 1702, la Corona hizo balance de estas expediciones a El Petén, concluyendo que si bien se abrieron diferentes caminos entre Yucatán y Guatemala, buena parte de los itzáes y sus vecinos seguían sin reducirse. ${ }^{15}$

\section{La expedición a la Montaña del Chol en 1699}

En las denominadas "Tierras Bajas Mayas", en el territorio que se extendía entre el ángulo sureste del Petén, el sur de Belice y la región del Golfo Dulce, se desenvolvían una serie de poblaciones con un patrón de asentamiento muy común. Estaban separadas unas de otras, formando pequeñas aldeas, con un grado de desarrollo político y social bajo, manteniendo cierto grado de independencia unas de otras. ${ }^{16}$ Para Jones esta dispersión era el reflejo de las presencias itzá y española en estas zonas, buscando muchos de estos pueblos refugio en regiones aisladas. Para el caso de lo mopanes, según Jones, a pesar de estos inconvenientes fueron capaces de mantener cierto grado de centralización política y territorial. ${ }^{17}$

Esta región, habitada por diferentes grupos de filiación chol, junto con mopanes, tipuanos y cehaches, al estar colindante con la confederación de los itzáes del centro del Petén, estuvo no sólo en la órbita de ésta, su agresividad y expansionismo, sino que se convirtió en su centro de abastecimiento. Pero asimismo, esa vecindad con los itzáes junto con las dificultades geográficas y el interés de las autoridades religiosas y políticas por su reducción, provocaron que desde la primera mitad del siglo xv hasta bien entrado el siglo xvı asistamos a diferentes expediciones para reducir a las comunidades indígenas allí instaladas. ${ }^{18}$ Aquellas,

\footnotetext{
${ }^{15}$ Hemos resumido la conquista, entrada y reducción de los itzáes siguiendo el trabajo de Caso (2002: 249-310). Véase también, Means (1974) y Jones (1998). La crónica de esta conquista se encuentra perfectamente descrita en Villagutiérrez (1985). Otra crónica que guarda mucha relación con la anterior es la de Valenzuela (1979).

${ }^{16}$ García (1985: 16).

${ }^{17}$ Jones (1998: 21-22).

${ }^{18}$ Una concisa pero clara recapitulación de las entradas que se produjeron en el área chol y vecinas desde Guatemala y Chiapas a partir del siglo xv puede consultarse en Von Houwald (1979: 123-138). Igualmente, remitimos al listado que ofrece Suñe (1994: 179-180).
} 
aunque nunca fueron constantes y persistentes, sirvieron para obtener informes y relaciones utilizados no sólo para conocer el entorno geográfico y la naturaleza del terreno sino también la condición y el temperamento de sus habitantes.

La expedición a la Montaña del Chol a principios de 1699, entre febrero y marzo, dirigida por el Sargento Mayor don Miguel Rodríguez Camilo, castellano del Castillo de San Felipe del Golfo Dulce y Alcalde Mayor del Puerto de Santo Tomás de Castilla y del pueblo de San Pedro Amatique, ${ }^{19}$ fue una incursión más de las habidas en estos territorios del sureste maya para reducir a los que denominaba como "indios infieles" y huidos diseminados por el área y enviada desde la Audiencia de Guatemala. ${ }^{20}$ Sin embargo, a diferencia de la mayoría de las entradas llevadas a cabo en esta área desde la segunda mitad del siglo xvl, no había un fin evangelizador en esta que se realizó a las Montañas del Chol, ni religioso alguno formando parte de la compañía al mando de Rodríguez Camilo. El objetivo era reducirlos y trasladarlos al lugar denominado Las Bodegas, en el pueblo del Señor San Antonio, en las inmediaciones del Castillo de San Felipe en el Golfo Dulce. Aquí serían instalados y concentrados entre indios de su misma habla, choles, con el fin de facilitar su control. Pero de igual manera que se sacaba y trasladaba población, la citada penetración se produjo en un momento de plena acometividad por incorporar al dominio colonial el área inmediata a las Montañas del Chol, El Petén.

El Sargento Mayor Miguel Rodríguez Camilo tenía como misión, por orden del Presidente de la Real Audiencia de Guatemala, Gobernador y Capitán General de esas Provincias, don Gabriel Sánchez de Berrospe, entrar a las Montañas del Chol y reducir los "indios infieles" (sic) que allí habitaban, concretamente los mopanes, "a donde llevo la mira, por ser la más gente y poblaciones grandes". ${ }^{21}$ Los mopanes, como la generalidad de los grupos humanos asentados en esta región, pese a estar mejor organizados y según las fuentes, como acabamos de señalar, ser mayoritarios y sus pueblos más grandes, los inconvenientes de la dispersión no impidieron que mantuviesen cierto grado de centralización política y territorial como señala Jones. ${ }^{22}$ Estudios recientes, si no contradicen formalmente a Thompson, que defiende la presencia en estos territorios de asentamiento

\footnotetext{
${ }^{19}$ El documento donde viene descrita la entrada del Sargento Mayor Don Miguel Rodríguez Camilo se encuentra en la Biblioteca Nacional de México (Fondo Reservado), Archivo Franciscano, (en adelante: вNм (Fr) - AF), Caja 59, exp. 1178, ff. 17r-21v

${ }^{20}$ Una vez constituido el presidio de El Petén en 1699, gracias a las ayudas para su mantenimiento, aunque escasas, provenientes de la Audiencia de Guatemala, entre las funciones del cabo principal del mismo se encontraba la reducción y congregación de los itzáes que vivian en las montañas aun por pacificar, Caso Barrera (2002: 311-320). Por lo cual, el interés de los gobiernos de Guatemala por controlar esta región era más que evidente, y así lo demuestra la entrada del Sargento Mayor Miguel Rodríguez Camilo al sureste y poniente de El Petén.

${ }^{21}$ вNм (FR) - AF, Caja 59, exp. 1178, f. 17r. El interés de los españoles por los mopanes, su reducción y conversión, venía determinado por la importancia estratégica de este pueblo al estar colindantes con los itzáes, Von Houwald (1979: 71).

${ }^{22}$ Jones (1998: 21-22).
} 
dispersos, pequeños pueblos y rancherías diseminadas por la selva, ${ }^{23}$ presentan novedades sobre la organización política de los pueblos que ocupaban las Tierras Bajas Mayas en pleno periodo colonial. Para el caso de los cehaches, pueblos de un nivel de organización similar a los mopanes, Juan Manuel Chávez Gómez señala que la organización política de sus pueblos en pleno siglo xvil se integraban en lo que él llama batabilob, donde gobernaban varios batabob o gobernadores. Cada batab o gobernador administraba autónomamente su territorio y la extensión de éste se basaba en el número de poblaciones dispersas con las que tuvieran algún vínculo. ${ }^{24}$

Rodríguez Camilo reunió una expedición de 83 personas, conformada por 16 indios del pueblo de Amatique, prácticos o guías de la Montaña, ${ }^{25}$ dos indios choles naturales de la Montaña, "de los que tengo poblados en las Bodegas, en el pueblo del Señor San Antonio", ${ }^{26}$ también utilizados como prácticos o guías, además de 36 infantes, así como 29 indios de la provincia de Casaguastlan utilizados de cargueros para abastos y provisiones.

La expedición salió del Castillo de San Felipe del Golfo Dulce, entre los lagos de Izabal y El Golfete, el 20 de febrero de 1699 utilizando piraguas y canoas que la llevaría a la desembocadura del río Dulce en el Golfo de Honduras, cerca del puerto de Santo Tomás de Castilla. Dos días después de salir al mar e iniciar un recorrido de cabotaje hasta llegar a las Barrancas (actualmente Barranco, en Belice) la partida recorrió 16 leguas $(88 \mathrm{~km})$. En las Barrancas soportaron los expedicionarios un temporal que por dos días obligó a suspender la marcha. El 25 de febrero después de recorrer cuatro leguas se introdujeron en el río Amas (actual río Moho, en Belice) donde sufrieron diferentes temporales en su recorrido. Perdieron abastos de pan y carne, pólvora y además parte de la expedición enfermó, especialmente uno de los dos guías choles, "que fue un gran desconsuelo", fundamental para transitar por las montañas del interior y llegar hasta el destino final, los mopanes. ${ }^{27} \mathrm{Al}$ cabo de unos días asentados en el río, intentando reparar los daños y atender a los expedicionarios enfermos y fatigados, y después de

${ }^{23}$ Thompson (1975: 105-106).

${ }^{24}$ Chávez (2006: 69). Véase al respecto Okoshi, Williams-Beck e Izquierdo (2006), y Caso (2002: 143-147).

25 Siguiendo los planteamientos de Thompson (1975: 120-121), estos amatiques hablaban chol manché y eran utilizados como "indios mansos" para facilitar y "apresurar la absorción en la cultura hispano-cristiana" de los indios manchés choles sacados de la "montaña". Asimismo, Villagutiérrez (1985: 364-365), da cuenta de la labor como "indios domésticos" que realizaron los indios amatiques en la entrada de 1696 cuando arribaron a la montaña por la parte del Golfo Dulce y "sacaron ochenta y cinco indios infieles, hombres y mujeres, con sus hijos" para bautizarlos, trasladarlos y poblarlos en el pueblo de Amatique.

${ }^{26}$ nNм (Fr) - AF, Caja 59, exp. 1178, f. 17r. El pueblo del Señor San Antonio, actualmente San Antonio, en Belice, aparece a lo largo de este documento como un poblado utilizado de avanzadilla hacia el interior de las Montañas del Chol, además de ser un lugar de asentamiento de indios reducidos de dichos parajes. Sus habitantes, como señala el mismo Rodríguez Camilo son choles, aunque más adelante les denomina "jicaques".

${ }^{27}$ Idem. 
haber recorrido 12 leguas $(66 \mathrm{~km})$ corrientes arriba, los expedicionarios llegaron el 3 de marzo a un embarcadero, desde donde partieron hacia el interior por tierra, "con grande trabajo y por los atascaderos y lluvias de agua, por Montaña tierra llana, siguiendo vereda de picadura". ${ }^{28}$ Tomando rumbo hacia el norte, a seis leguas del embarcadero, la expedición llegó a un pueblo de indios choles o "jicaques" de los que tenía poblados en las Bodegas, en el pueblo de Señor San Antonio. ${ }^{29}$ Sus casas estaban dispersas, a distancia de media legua y una legua, una de otra, y tenían provisiones de maíz en abundancia, así como maíz verde en las milpas y otros mantenimientos en sus huertas; sin embargo, las aguas, "de posas rezagadas y turbias, bien malas y gruesas por no haber río de corriente inmediato a dicha población", hacían imposible que "gente de razón" pudiese habitar dicho lugar, según Rodríguez Camilo. ${ }^{30}$

La llegada a estos parajes sirvió para hacer un recuento del estado de la expedición, después de trece días de iniciada y estando en las puertas de las Montañas del Chol. Por lo pronto el balance podría considerarse negativo: el indio chol o "jicaque" enfermó, uno de los dos prácticos o guías conocedores de la Montaña y de los mopanes, y natural de esta comarca, murió; el otro práctico chol también cayó enfermo; además, se tuvo que dejar en estos lugares a trece enfermos imposibilitados de seguir el ritmo (dos criados, un indio amatique y diez indios cargueros), al cuidado de dos indias amatiques de la expedición.

Ante esta situación Rodríguez Camilo tuvo que tomar una serie de medidas. En primer lugar, previno a la hueste que le acompañaba, especialmente a la infantería, que si no se encontraban con suficientes fuerzas para continuar adelante, por las dificultades que iban a encontrarse en la Montaña, sería conveniente que permaneciesen con los que se quedaban por enfermedad. Por otra parte, consultó con los indios amatiques, utilizados como prácticos o guías en la expedición, si para el buen éxito de ésta era conveniente enviar urgentemente al Castillo de San Felipe una canoa para que trajese nuevos indios choles reducidos en las Bodegas conocedores de la Montaña y de los mopanes. El Sargento Mayor Rodríguez Camilo tenía su opinión al respecto,

[...] haciéndoles mis razonamientos de los gastos que para dicha empresa ha hecho Su Majestad y que era más conveniente el esperar en dicha población a dichos

\footnotetext{
28 lbidem, f. $17 \mathrm{v}$.

${ }^{29}$ El Sargento Mayor Rodríguez Camilo usa indistintamente los términos "choles" y "jicaques" para referirse a los indios reducidos en las Bodegas del pueblo del Señor San Antonio. El término "jicaque", en el contexto de la entrada que hace Rodríguez Camilo a la Montañas del Chol, debemos interpretarlo, como lo señala su origen etimológico náhuatl, como indio levantado o huido: Jicaque: en nahuatl icaque, cf. Icac, estar levantado; icaque, están levantados, en Siméon (2006: 164-165). No hay que confundir a estos "jicaques" o choles, levantados y huidos, con los indios Jicaques o tolupanes de Honduras, asentados en el departamento de Yoro, y en la Montaña de la Flor, que genéricamente eran denominados 'jicaques' porque por distintos medios también evadian la acción de la conquista; véase Chapman (1971: 751-753).

${ }^{30}$ вмм (Fr) - AF, Caja 59, exp. 1178, f. $17 \mathrm{v}$.
} 
prácticos, que no ir al accidente, de no poder dar con la población grande de los mopanes, y no ser ellos [los cargueros amatiques] prácticos de dicha Montaña del Chol, $[\ldots]]^{31}$

Los amatiques, sin embargo, indicaron que era más conveniente seguir la marcha hasta la cabecera de Ellasar (sic), donde harían un alto con la infantería y explorarían la zona, pues tenían noticias de la presencia de algunas casas y ranchería de indios "jicaques" (choles) en dicho lugar. Una vez allí se podrían capturar algunos indios como guías para llegar a la tierra de los mopanes y otros lugares. Esta postura era la más adecuada, según los guías amatiques, para no demorar la expedición, además de no deteriorar más el estado de salud de buena parte de la expedición, que se podría empeorar si se atrasaba la marcha. Rodríguez Camilo, al final, ante la promesa de los amatiques de conseguirle guías choles para seguir el camino hacia el Mopán, se decantó por el parecer de aquéllos,

[...] lo uno porque de esperar en dicha población a que me lo trajesen de dicho Castillo [de San Felipe] era tiempo de doce días dispuesto al contratiempo de acaecer gastos a Su Majestad, y que en dicha dilación podía enfermar la más de la gente por la experiencia de los enfermos que tengo al presente y consumir los mantenimientos de más sustancia de pan y carne $[\ldots]^{32}$

Así, el 5 de marzo se emprendió la marcha en dirección al norte con el objetivo primordial de encontrar prácticos para llegar a los mopanes. A seis leguas del inicio de la misma encontraron una población de tres casas, desordenadas, apartadas unas de otras, y sin gente, pero con provisiones de maíz, las milpas sembradas, además de platanales, yucas, chiles y otros productos de la huerta, muestra que debió ser una población importante. El abandono del lugar nos da a entender la desconfianza y el recelo que existían entre los indígenas hacia estas expediciones y las consecuencias que podrían derivarles: el traslado forzoso fuera de sus lugares de origen, para ser reducidos y congregados en poblaciones mayores e iniciar el proceso de catequización. Para la expedición que estamos analizando, y según la información que nos aporta este documento, el papel de pueblo reductor o congregador lo juega el sitio de las Bodegas, en el pueblo de Señor San Antonio, en las cercanías del Castillo de San Felipe, a más de trece días de distancia en jornadas de caminata y piraguas.

El 6 de marzo el Sargento Mayor Rodríguez Camilo ordenó explorar las veredas y caminos por donde los indios de estos lugares transitaban y comerciaban sus frutos. Resultado de estas incursiones fue la captura de un indio de nación "Yasales" (sic), que dio información de la existencia de otros 16 indios, entre varones y mujeres, a tres leguas al nornordeste de la anterior población, en dos casas pobladas y con provisiones de alimentos. Una vez localizados, les fue to-

\footnotetext{
${ }^{31}$ Ibidem, ff. $17 \mathrm{v}-18 \mathrm{r}$

32 Ibidem, f. 18 r.
} 
mada declaración sobre las poblaciones y grupos que existían en los alrededores. La información que recibió Rodríguez Camilo fue que sólo habían mantenido comunicación y trato con gente de una población "de hasta diez casas de a tres o cuatro familias en cada una, llamada Bolón", ${ }^{33}$ que se hallaba a tres días de camino y con los que mantenían tratos. Es más, dejaron constancia en sus declaraciones que intentaron poblarse en el pueblo de Bolón, junto con la gente de las tres casas que la expedición halló despoblada el día 5, después de la última entrada que realizaron los amatiques a su pueblo, y no se lo permitieron. Fruto de esta incursión pasada eran muchos de los choles que estaban poblados en las Bodegas, en el pueblo de Señor San Antonio, algunos de los cuales eran parientes de los que fueron interrogados.

La negativa de los de Bolón a dejarlos poblarse en sus términos les generó un deseo de venganza y por ello se ofrecieron ayudar a la expedición de Rodríguez Camilo a llegar al citado pueblo. Además, así lo certifica y firma el Sargento Mayor, "estaban consolados y contentos de que yo los sacase de su población por ser pocos y perseguidos, con sus parientes a dichas Bodegas, donde también se poblarán en el pueblo del Señor San Antonio". ${ }^{34}$ ¿Debemos creer las palabras que certifica y firma el Sargento Mayor Rodríguez Camilo donde estos indios aparecen como sumisos, contentos y deseosos de ser trasladados con sus parientes a las Bodegas, cuando el origen del enfado tiempo atrás con los de Bolón era la negativa a asentarse en su pueblo huyendo precisamente de las acometidas de los indios amatiques enviados por la Audiencia de Guatemala para intentar su reducción? La respuesta la revela el mismo Rodríguez Camilo cuando el día 9 de marzo envió a los indios, que denomina como "apresados", junto al indio chol enfermo que le quedaba de guía y otros enfermos, con escolta de un soldado de su compañía e indios cargadores, a la población donde tenía a todos los enfermos. ${ }^{35}$

El mismo 9 de marzo siguió su marcha por la montaña ayudado por uno de los indios "apresados", utilizado como explorador para lograr y asegurar el trabajo de la compañía. Tomando ahora derrotero hacia el oeste, atravesaron ríos caudalosos difíciles de vadear en época de lluvias. A distancia de diez leguas del anterior pueblo llegaron a una ranchería, "y de asalto apresé trece personas... y el cacique de dicha gente malherido de una mano, por haberse opuesto a la demostración de la defensa osadamente contra los dichos amatiques..." ${ }^{36}$ Después de curar sus heridas llegó la advertencia del Sargento Mayor hacia el cacique, donde le hizo ver desde el peligro al que se expuso, junto a sus gentes, por enfrentarse

\footnotetext{
$33 \mathrm{Ibidem}$, f. 18v. Como ya hemos referido, estos pueblos estaban agrupados políticamente al nivel aldeano, por lo que cada uno tenía su jefe o jefes, y en muchas ocasiones los nombres de los poblados son en realidad los de los jefes de los mismos. Véanse Thompson (1975: 105), Caso (2002: 146-147) y Chávez Gómez (2006: 68-69).

${ }^{34}$ Idem.

${ }^{35}$ Idem.

36 lbidem, f. 19r.
} 
a los amatiques, hasta las virtudes de solicitar la conversión al cristianismo y el alejamiento de sus idolatrías. El interés de Rodríguez Camilo era sacarlos de sus tierras y llevarlos a poblar a las Bodegas, "con la misma gente de su nación", por lo que podemos suponer que eran choles, donde se les "vestiría y les daría hachas y machetes y tierras para sus casas y milpas". ${ }^{37}$ Es decir, incluirlos en el programa de reducción y catequización que se venía desarrollando en el sitio de las Bodegas, en las inmediaciones del Castillo de San Felipe. Los agrupamientos en zonas controladas hacían posible una mejor reducción, e intentaban poner fin a un patrón de asentamiento disperso, al que nunca estuvieron preparados los evangelizadores y autoridades políticas, y sacar los mayores beneficios económi$\cos$, políticos y espirituales a la misma.

La colaboración del cacique y de sus gentes —de nación "canvoles" según consta en el documento-, para conocer las distancias de otras poblaciones cercanas y las relaciones que tenían con ellas, especialmente con el pueblo de Bolón, fue significativa. Por lo pronto, les informó que ellos eran pocos y se sentían acosados por otras "naciones". La declaración que realizó fue importante porque en cierta manera hacía un balance general del panorama etnográfico, no sólo en los alrededores de su pueblo, sino de toda el área del Petén, incluyendo a los mopanes:

[...] que distancia de medio día está el dicho pueblo de Bolón, que según me señalan está al oeste, de donde se sigue distancia de dos días de camino la población de otro pueblo grande y de mucha gente, de donde se siguen las poblaciones de los tesquenes distancia de otros dos días, asimismo con mucho número de gente, desde donde se siguen grandes pueblos de la nación solques, con mucha gente, que según razón están hacia cuadrillería del mar con otras muchas diferentes naciones, que están pobladas en diversos ríos y parajes y tierra adentro se siguen muchas poblaciones nación mopanes con tres pueblos copiosos de casas de hasta veinte zontes de cacao de gente, que según reputan dichos indios a cuatrocientos granos cada un zonte, son ocho mil personas, $[\ldots]$ y que dichos mopanes y otras naciones por recelo de que los españoles de Guatemala y Campeche en las conquistas pasadas los habían perseguidos, habían desamparado sus poblaciones antiguas y poblado en las referidas, de donde dicen tienen noticias que confinan con los agizaes y petenes de la laguna $\left[\ldots||^{38}\right.$

En la mañana del 10 de marzo, la expedición asaltó el pueblo de Bolón, que se extendía desordenadamente en un cerro, apartadas las casas unas de otras y con bastantes milperías de elotes, frutos de mantenimiento y algodón, y clima más fresco y mejores aguadas que los asentamientos anteriores. Treinta y dos personas fueron apresadas en esta acometida, pero ello no evitó que alrededor de otras trescientas huyeran, entre ellas el cacique Bolón, a pesar de que su ma-

\footnotetext{
${ }^{37}$ Idem.
}

38 Idem. 
dre y algunos familiares, siempre en palabras del Sargento Mayor, "les dieron a entender que no se fuesen de sus casas y dejasen sus milpas, que los españoles venían de paz". De todas formas, el discurso de las autoridades, que en nombre de Su Majestad y de la Audiencia de Guatemala se presentaban para reducir a los indios infieles y huidos en la zona colindante a los itzáes y petenes, seguía siendo el mismo con estos indios bolones: poblamiento en las Bodegas donde estarían libres de los mopanes, sus enemigos, donde se les daría ropa, hachas, machetes "y otras cosas con que se mantienen los españoles, y tendrían con ellos su trato y comunicación". ${ }^{39}$

Además de la importancia que el Sargento Mayor Miguel Rodríguez Camilo le daba a la reducción y traslado de estas poblaciones a las Bodegas en el pueblo de Señor San Antonio, la información que se podía obtener de los pueblos que se sometían, como de sus vecinos próximos, de sus conexiones y relaciones, eran fundamentales para que la expedición avanzara debidamente. Así, desde antes de llegar a Bolón tuvo noticias directas de los mopanes, el objetivo final de su entrada. Y fue en Bolón donde las declaraciones de los indios apresados, "invitados" a poblar en las Bodegas, revelaban el comportamiento y la manera de proceder de los mopanes con los pueblos colindantes. Expusieron los naturales de este pueblo cómo en sus tierras fueron perseguidos por ellos, "que eran muchos y valientes", que les habían robado y matado a muchos de su pueblo, además de llevado a algunas de sus mujeres. Por esta razón, su temor y seguridad, solicitaban su traslado a las poblaciones de las Bodegas. Pero a otras naciones, además de los mopanes, reconocían los naturales de Bolón:

[...] respecto de que los Saques que miran para la costa de la mar, es nación muy poblada, que confina con Chichilac y Cantelac y Cacala, términos de Campeche; y por lo que toca a la nación Mopanes, es mucha más gente poblada, tanto camino como trece días se puede dar, según cuentas hacen con tres pueblos en sus distritos, con la copia de gente que declaran los antecedentes de donde al fin de dicha tierra entran los Agizaes y Petenes de la Laguna y Cayo, y que de la parte del poniente debajo de donde se pone el sol que demora al oeste rumbo antecedente, están poblados la nación de los Camoles, de mucha gente, de donde se siguen los Yulumales, de mucha gente, de donde está otra nación Cholgimía, que confina el Caxabón, que hay por dichas partes. ${ }^{40}$

Los de Bolón señalaron que a cualquier lugar que se anduviera de los arriba indicados, partiendo desde su pueblo, se podía hallar población cada jornada de caminata. Asimismo destacan que eran pueblos pacíficos y con comunicaciones entre ellos, pero dada la presión que desde los últimos años estaban teniendo de los españoles, por recelo y miedo a traiciones, se escondían unos de otros. ${ }^{41}$

\footnotetext{
39 Ibidem, f. 19v.

${ }^{40}$ Idem.

41 Ibidem, f. 20r.
} 
Rodríguez Camilo, tomando en cuenta estas declaraciones de los bolones así como las realizadas con anterioridad, estaba presto a seguir la reducción considerando las solicitudes de estos naturales. Por una parte, atraer por medios pacíficos a los bolones que huyeron; por otra, someter a los mopanes para vengarlos, como enemigos suyos que eran. El Sargento Mayor estaba en la mejor disposición, no sólo de catequizarlos, sino de ponerles guarnición militar de soldados españoles en sus términos para su seguridad y que pudieran ayudar a la entrada a los mopanes, la empresa que le trajo a estas tierras por mandato del Presidente de la Real Audiencia de Guatemala don Gabriel Sánchez de Berrospe. Para ello había que aguardar la llegada de socorro de gente y abastecimientos. Sin embargo, fueron los indios amatiques, que ejercieron como guías desde el inicio de la expedición, quienes mostraron al Sargento Mayor la realidad de ésta:

[...] estaban los más enfermos y de mucho riesgo de la vida, que para cualquier parte de las que me siguiesen les precisaba cargarlos, y que los sanos aún no podían con sus maletas y armas, y demás que estaban sumamente lastimados de los pies y quebrantados de todo el cuerpo, imposibilitados a cualquier función, y sin valor para ella, y que no habían en su pueblo hecho milpas y de pasarse el tiempo para ello, pasarían grandes necesidades. ${ }^{42}$

La solicitud de los indios amatiques de acabar con su participación en la expedición y volver a sus lugares de origen fue el reconocimiento por parte del Sargento Mayor Rodríguez Camilo de que ésta se encontraba consumándose. No sólo era este problema, sino la situación de los denominados "indios infieles apresados" que había que trasladar a las Bodegas para su reducción, los enfermos de su infantería, y los pocos números de ésta disponibles para seguir en el intento de llegar a los mopanes. Por lo tanto, tomando en consideración esta situación y la necesidad de utilizar la mayor parte de los indios cargueros sanos para trasladar enfermos, "indios infieles" y los avíos, Rodríguez Camilo decidió, conjuntamente con el resto de la oficialidad que le acompañaba, salir de Bolón, "cuidando así a dichos indios infieles, como a dichos indios enfermos, aliviándolos de las armas y maletas, y cargando algunos de ellos con los sanos y buenos, que me asisten de guarnición". ${ }^{43}$

Detrás de la actitud de los amatiques de regresar a las Bodegas se pueden deducir otras intenciones. Ellos eran conocedores de la región a reducir, por ello participaban como prácticos o guías en esta expedición. Cuando en la decimotercera jornada, antes de acometer la entrada a la Montaña, el Sargento Mayor Rodríguez Camilo se dirigió a los amatiques para tantear la posibilidad de pedir ayuda al Castillo y traer nuevos guías choles, después de las bajas de los que partieron inicialmente, aquellos indicaron que lo más conveniente era proseguir,

\footnotetext{
${ }^{42}$ Idem.

${ }^{43} \mathrm{Ibidem}$, f. $20 \mathrm{v}$.
} 
desechar esa ayuda y que se conseguirían guías en los parajes que fueran transitando. Continuar la entrada a los mopanes sin guías era un freno indudable a la expedición. Podría entenderse este comportamiento de los amatiques, junto a la decisión final de volverse, según ellos por el mal estado físico en que se encontraban y "que no habían en su pueblo hecho milpas", ${ }^{44}$ como una especie de artimaña que servía de freno a la expedición y con ello no alcanzar los asentamientos montaraces donde podrían tener amigos e incluso familiares.

Coincidió el final de esta expedición a los mopanes con noticias que llegaron el mismo día 10 de marzo procedentes del gobernador del pueblo de Amatique, don Simón de la Luna, de la presencia de un navío y varias piraguas dirigiéndose al Castillo de San Felipe, que podría ser de piratas, y por cuya causa se había puesto el Castillo en armas. El Sargento Mayor precipitó su vuelta al Castillo ante estos hechos con toda la expedición, pese a las penosas condiciones en las que viajaba la misma. En ocho días efectuaron el trayecto de vuelta que en condiciones normales se realizaba en dos semanas. Ya en las cercanías del Castillo, asegurando a los indios reducidos en esta expedición y a los enfermos con parte de la infantería, Rodríguez Camilo se adelantó con el resto de ésta y las noticias que recibió fue que se trataba de una fragata pequeña de aviso procedente de La Habana, y para nada enemigos de la Corona. ${ }^{45}$

Sin embargo, los resultados de la expedición, pese a no entrar finalmente a someter los mopanes, amparándose en el estado físico de la expedición y a solicitud de los indios prácticos o guías amatiques, podrían considerarse como positivos para el Sargento Mayor. De los sesenta indios finalmente reducidos, entre hombres, mujeres y niños, llegaron al pueblo de San Antonio de las Bodegas cincuenta y seis, pereciendo el resto de "accidentes rigorosos de catarro". Estos se unirían a los indios allí instalados, de una expedición anterior, "aunque son de diferentes parcialidades y naciones". Las noticias que obtuvo de los mopanes a partir de las informaciones facilitadas por los naturales que traía a reducir eran suficientes como para asociarlos de indios dificiles y peligrosos, así como azotes de poblaciones vecinas. Por ello, los indios reducidos, en palabras de Rodríguez Camilo, "quedan consolados, mayormente favorecidos de los españoles y libres de la nación de los mopanes". 46

\footnotetext{
44 lbidem, f. 20r.

45 lbidem, ff. $20 \mathrm{v}-21 \mathrm{r}$.

46. lbidem, f. $21 \mathrm{v}$.
} 


\section{Fuentes documentales}

\section{Archivo General de Indias}

AGı, Guatemala, 152-153, "Autos hechos sobre la reducción del Chol y Lacandón y Mopán, 1695".

AGI, Guatemala, 181, "Relación del Padre Fray Juan Ezquerra O.P. sobre la Provincia del Manché, 1605".

Biblioteca Nacional de México (Fondo Reservado), Archivo Franciscano BNM (FR) - AF, Caja 59, exp. 1178, "Entrada a la Montaña del Chol a principios de 1699 , entre febrero y marzo, dirigida por el Sargento Mayor don Miguel Rodríguez Camilo, castellano del Castillo de San Felipe del Golfo Dulce y Alcalde Mayor del Puerto de Santo Tomás de Castilla y del pueblo de San Pedro Amatique".

\section{Bibliografia}

Bracamonte y Sosa, Pedro

2001 La conquista inconclusa de Yucatán. Los mayas de la montaña, 1560-1680. México: Ciesas/Miguel Ángel Porrúa (Colección Peninsular).

Caso Barrera, Laura

2002 Caminos en la selva. Migración, comercio y resistencia. Mayas yucatecos e itzáes, siglos XVIl-XIX. México: El Colegio de México/Fondo de Cultura Económica.

Chapman, Anne

1971 "Supervivencias de la organización dual entre los Jicaques de la Montaña de la Flor (Honduras)", América Indígena, 31 (3): 751-763, México: Instituto Indigenista Interamericano.

Chávez Gómez, José Manuel A.

2001 Intención franciscana de evangelizar entre los mayas rebeldes. México: conacultA. 2006 "La recreación del antiguo espacio político. Un cuchcabal kejache y el na'al hejach Chan en el siglo xvı", Nuevas perspectivas sobre la geografia política de los mayas. pp. 57-79, Tsubasa Okoshi Harada, Lorraine A. Williams-Beck y Ana Luisa Izquierdo (eds.). México: Universidad Nacional Autónoma de México, Universidad Autónoma de Campeche y Foundation for the Advancement of Mesoamerican Studies, Inc.

De Vos, Jan

1988 La paz de Dios y del Rey. La conquista de la selva lacandona (1525-1821). México: Fondo de Cultura Económica.

García Añoveros, Jesús María (Edición e Introducción)

1985 Historia de la conquista de Itzá, Juan de Villagutiérrez Sotomayor. Madrid: Historia 16. 
Jones, Grant D.

1990 Maya Resistente to Spanish Rule. Time and History on a Colonial Frontier. Albuquerque: University of New México Press.

1998 The Conquest of the Last Maya Kingdom. Stanford, Calif: Stanford University Press.

León Pinelo, Antonio

1960 Relación que en el Consejo Real de las Indias hizo el Licenciado Antonio de León Pinelo, Relator de su Alteza, sobre la pacificación y población de las provincias del Manché y Lacandón, que pretende hacer don Diego de Vera Ordónez de Villaquirán, Caballero de la Orden de Calatrava, año de 1638. Guatemala: Editorial Universitaria.

Means, Philip A.

1974 History of the Spanish Conquest of Yucatán and of the Itzas. New York: Kraus Reprint.

Okoshi Harada, Tsubasa, Lorraine Williams-Beck y Ana Luisa Izquierdo (eds.)

2006 Nuevas perspectivas sobre la geografia política de los mayas. México: Universidad Nacional Autónoma de México, Universidad Autónoma de Campeche y Foundation for the Advancement of Mesoamerican Studies, Inc.

Ruz, Mario Humberto

1992 "El conquistador y el jurisconsulto. Testimonios sobre el Itzá", Estudios de Cultura Maya, XIX: 335-395, México: Instituto de Investigaciones Filológicas/ Centro de Estudios Mayas, Universidad Nacional Autónoma del México.

\section{Schumann Gálvez, Otto}

1997 Introducción al maya mopán: los itzáes desde la época prehispánica hasta la actualidad. Estudio interdisciplinario de un grupo maya. México: Instituto de Investigaciones Antropológicas, Universidad Nacional Autónoma de México.

2000 Introducción al maya itzá. México: Instituto de Investigaciones Antropológicas, Universidad Nacional Autónoma de México.

Siméon, Remi

2006 Diccionario de la lengua náhuatl o mexicana. México: Siglo XXI Editores.

Stone, Doris Z.

1932 Some Spanish entradas, 1524-1695: A revision of the Data on Spanish entradas into the Country of the Lacandon and Ahitza. New Orleans: Tulane University.

Suñe Blanco, Beatriz

1994 "Los choles de la región del Golfo Dulce: etnografía histórica según la documentación del Archivo General de Indias", Memoria del Primer Congreso Internacional de Mayistas, vol. III, 150-184. México: Instituto de Investigaciones Filológicas/Centro de Estudios Mayas, Universidad Nacional Autónoma de México. 
Thompson, J. Eric. S.

1975 Historia y religión de los mayas. México: Siglo XX.

Tovilla, Martín Alfonso

1985 Relación histórica descriptiva de las Provincias de la Verapaz y de la del Reino del Manché del Reino de Guatemala, en Juan de Villagutiérrez Sotomayor. Historia de la conquista de Itzá (edición de Jesús María García Añoveros): Madrid: Historia 16.

Valenzuela, Nicolás de

1979 Conquista del Lacandón y conquista del Chol (editado y comentado por Götz Freiherr Von Houwald), 2 tomos. Berlín: Biblioteca Iberoamericana. Colloquium Verlag.

Villagutiérrez, Juan de

1985 Historia de la conquista de Itzá (edición de Jesús M. García). Madrid, Historia 16 (Crónicas de América, 13).

Von Houwald, Götz Freiherr

1979 Nicolás de Valenzuela: Conquista del Lacandón y conquista del Chol, Tomo II: Comentario. Berlin: Biblioteca Iberoamericana. Colloquium Verlag.

Ximénez, Fray Francisco O.P.

1973 Historia de la Provincia de San Vicente de Chiapa y Guatemala de la Orden de los Predicadores, Libros IV y V. Guatemala: Sociedad de Geografia e Historia. 


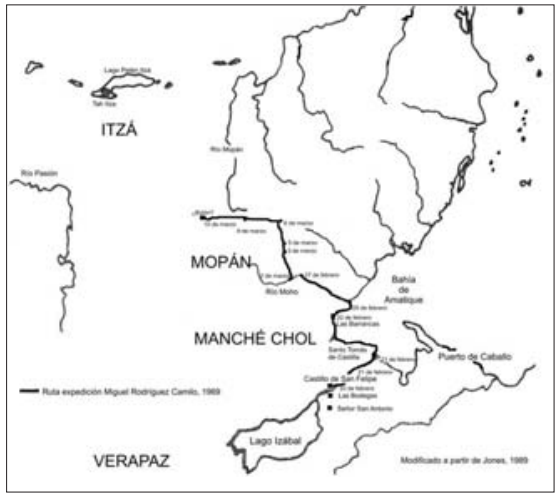

